\title{
Developing retention strategies based on customer profitability in telecommunications: An empirical study
}

Received: 21st September, 2004

\section{Evangelos Xevelonakis}

is Managing Director of Swiss Valuenet. He graduated in economics and computer science and has a doctorate in customer relationship marketing from the University of Zurich. Dr Xevelonakis has headed several segmentation projects involving customer profitability and customer needs in the telecommunications and banking sectors. Before joining Swiss Valuenet he headed the Strategic Customer Relationship Management (CRM) Department of Swisscoms where he was responsible for customer segmentation, customer profitability and for the whole business intelligence process. He has also worked for Credit Suisse, where he was responsible for setting up the database marketing process for direct banking. His research interests involve predictive modelling for churn management, customer segmentation, customer profitability and designing concepts for strategic CRM. He also lecturers in CRM and data process modelling at the Zurich University of Applied Science.

Abstract Research evidence shows that telecommunications companies fail to make their CRM efforts pay off. This is probably due to a lack of capability to develop effective customer strategies based on customer profitability. Reducing the churn rate in the industry is not enough. Companies must be able to plan and execute profitable campaigns, taking into account both customer risk and customer profitability. Controlling and evaluating the campaign's results is a crucial factor. In this paper, this deficiency is addressed by proposing a framework for building effective customer strategies based on customer behaviour, customer profitability and customer risk. Empirical results are analysed and discussed.

\section{THE TELECOMMUNICATIONS MARKET}

The telecommunications sector is changing radically. The changes are driven by a combination of market, business and technological forces. There are many factors that influence the market:

- The globalisation of the economy is forcing many multinationals to expand into new markets. These companies look for a single provider to meet all their telecoms needs.

- Telecom operators looking for new revenue streams are entering the international market place.
- New technologies - like wireless, digital subscriber line (DSL) and voice over internet protocol (VoIP) are enabling new service opportunities. The demand for bandwidth and high-speed access is growing, driving the development of new services such as wireless broadband and DSL.

- Customer awareness and knowledge is increasing. Customers want services that satisfy their unique needs and demand reliable service delivery at competitive prices. Information must be easily accessed, anytime, anywhere and anyhow. One stop shopping must be possible 
and a choice of service providers available.

The real differentiation in the market will not be the technology or the services or the prices, it will be the ability to: deliver a better quality service and responses to customer requests; keep customers informed as orders are being processed; reduce costs and not prices; be faster at providing service inquiries. The main critical success factors and risks facing businesses today remain the same: falling margins, increasing customer expectations, improving productivity and customer churn and fraud.

In the wireless age, the days of double-digit growth are over.

Competitors are now fighting for one another's customers. In wireline, real revenues for local and long distance calls are falling. New entrants to the market are taking market share from incumbents. In order to stabilise today's depressed prices, operators have to improve margins. Until recently, most telecommunications companies were busier their expanding customer bases than increasing existing customers' value for money. Reducing churn by offering discount plans and other incentives led to unprofitable customers. Trying to contain the surge in unpaid bills by tightening credit limits on new applicants, resulted in many would-be profitable customers being turned away.

It is a common belief in the CRM world that retaining existing customers costs less than acquiring new ones. Retention campaigns aim, therefore, at reducing the churn rates. Customers receive binding offers in the form of rebates, discounts etc. Often though, retention campaigns are designed and planned with the aim of minimising customer attrition. Campaign success is measured by reduction in churn rates without differentiating between high value and low value customers.

Customer loyalty is sometimes bought at a price that exceeds the customer value.

As a consequence, for example, there are emerging segments of customers that tend to profit from provider CRM strategies. These customers are loss-making and should not necessarily be included in retention offers

Taking into account customer profitability implies finding the optimum balance between campaign costs (eg rebate) and churn rate. ${ }^{1}$ If one ignores customer profitability, one can successfully reduce churn rates by offering arbitrarily high rebates. Taking customer value into account, however, places a limit on the possible discount for each customer. The churn rate may remain high but the campaign can be more profitable.

This paper presents a general formulation and an example for valuing retention campaigns taking different factors into account.

Calculating a negative net present value (NPV) for a planned campaign should not be an absolute criterion for not carrying out the campaign. Strategic considerations dictating a certain marketing strategy can be hard to quantify in a simple mathematical model. Use of a simple profitability model, however, offers a quick additional insight into the business objectives and protects against excesses aimed at reducing churn rates at any cost.

\section{DEFINING A CUSTOMER STRATEGY - RETAINING PROFITABLE CUSTOMERS}

\section{Background}

The most important reason for investing in retention of profitable customers is the cost of acquiring new customers compared with the cost of retaining 
existing customers. International research by Coopers \& Lybrand has shown that it can be at least five times as hard to acquire new customers than to keep existing customers (and sometimes up to 25 times as hard). ${ }^{2}$

The objective of a customer retention strategy should be to nurture long-term relationships with customers through trust, responsiveness, customised services and reliability. Key to this strategy should be the ability to utilise knowledgeable, intelligent customer information for the benefit of customers and to offer them seamless quality of services. Thus the strategy should offer segment-specific plans to meet customers' needs and wants.

Customer care, therefore, had become one of a telecommunications company's most important activities in order to provide superior customer satisfaction and build excellent relationships with customers.

In the competitive and deregulated environment of the telecommunications industry, customers have more choice in selecting service providers.

When customers are considering whether to keep an existing supplier or to change, there are three factors they think about: ${ }^{3}$

- The quality of the service or product

- The price

- The quality of customer service

Dissatisfaction with the service is a key factor in determining whether or not a customer remains with a supplier. Where price and product features are quite similar, customer care is a prime differentiator in a deregulated customer focused market. Seamless customer service is a real competitive advantage, because it is much harder to imitate superior services than prices.

Employees with customer contact have to know what a customer is and what they want.

- The customer is the most important person the company will interact with - be it in person, over the telephone, by postal or electronic mail or by any other communications channel.

- The customer is a person who brings their wants and their money to the company.

The statements above mean that everyone employed by the company is responsible for meeting customers' needs. This cultural behaviour has to be implemented within the company and it has to be initiated by the management top-down.

As mentioned, the quality of service is the most important factor for improving customer relationships and unless employees are concerned about this in their dealings with customers, good quality of service will not be achievable.

\section{Quality of service factors}

To succeed in offering superior services to customers, the company has to identify service factors and the quality of these service factors. So what are the key factors in delivering high quality services?

- Reliability — delivering consistent and timely services.

- Knowledge - understanding the customer's situation.

- Empathy - offering individual care. Listening to the customer's requirements and problems. Demonstrating understanding of the customer's situation.

- Responsiveness — demonstrating willingness and readiness to solve problems. 


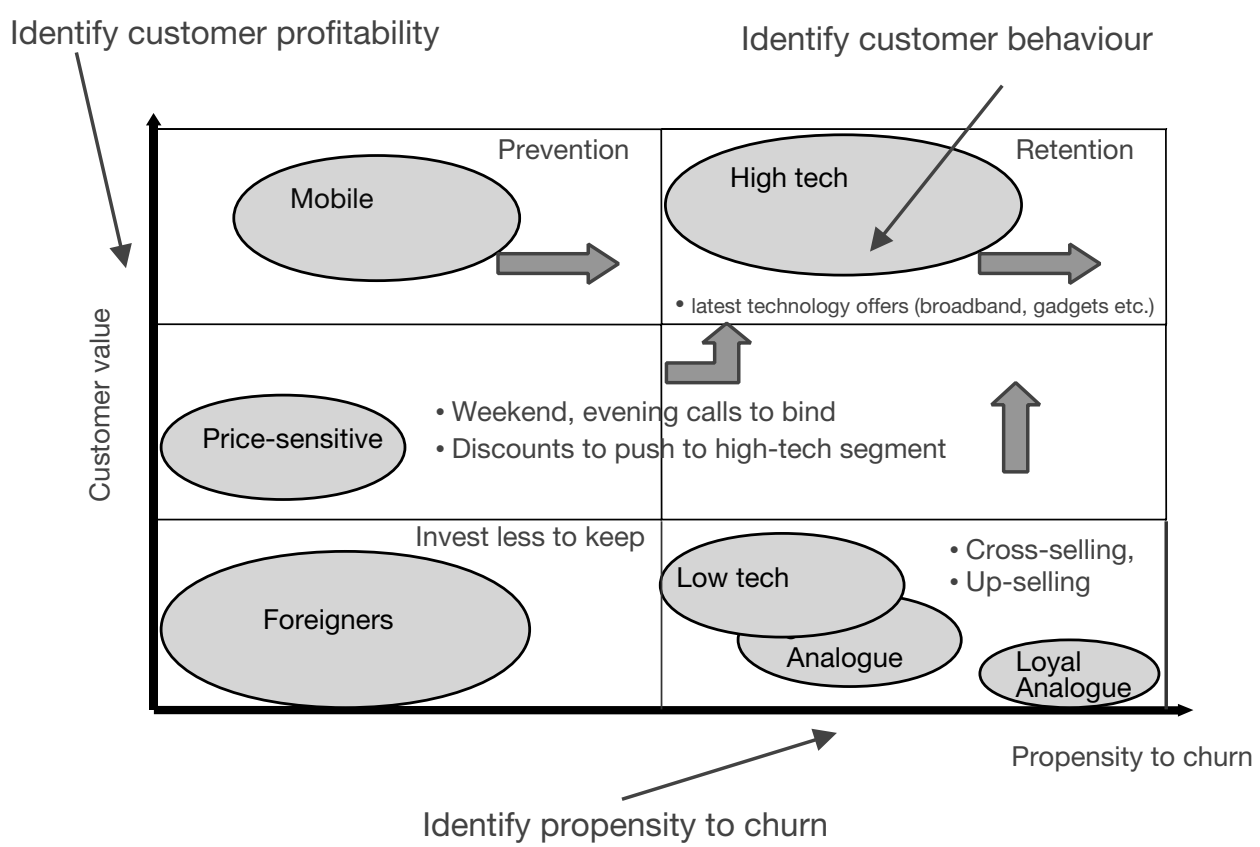

Figure 1: The customer portfolio based on customer value, propensity to churn and identified clusters

\section{Cultural behaviour}

The 'customer-company' relationship comprises a constant four-step cycle of relationship development each step requires different cultural behaviour skills.

— Receiving — being prepared for customers. This means anticipating what customers will want and need and making the customer feel welcome.

— Understanding — understand the customer's position, 'listening' and 'asking the right questions' skills. Without understanding, one cannot move to the next stage.

- Helping - offering information and options to the customer. During this stage employees should be making the move from getting information to providing a solution. They should be wary, though, of guaranteeing the customer something that they cannot or do not have the authority to deliver. Finally, employees should make sure that the customer agrees with the terms and conditions offered him/her.

— Keeping — the most important thing is to ensure that the customer's entire needs have been met in order to continually keep the customer doing business with the company. Keeping skills involve checking for satisfaction and following up to ensure all outstanding actions are resolved satisfactorily.

In order to define an effective customer retention strategy, companies have first to understand the customer behaviour using clustering methods; secondly they should define the propensity to churn using churn modelling; and thirdly they should identify customer profitability. Based on those propensity to churn and customer profitability parameters, companies will be able to build a customer portfolio and define the right strategies (see Figure 1). Based on empirical research the author has created a seven-step 
framework to develop effective customer strategies. ${ }^{4}$ The seven steps are:

1 Analyse internal and external data.

2 Build appropriate customer clusters.

3 Identify customer profitability.

4 Identify the propensity to churn.

5 Create a customer portfolio.

6 Apply customer profitability and propensity to churn to the identified clusters to design loyalty campaigns.

7 Design and carry out profitable campaigns.

This paper further examines how these customer profitability parameters can be established, based on the above framework.

\section{Customer clustering - Understanding customer behaviour}

Customers, shareholders and employees must recognise that the success of any business depends on its ability to know what customers need and deliver it. A customer segmentation framework provides essential direction for the delivery of a combination of basic and complex bundled products, services and pricing packages.

The customer contact cycle (Figure 1) is a useful way of viewing customer relationships from first awareness through sales and fulfilment to the point where they are upgrading or enhancing their services. Each interaction is an opportunity to fulfil the needs and wants of the customers. The customers' needs (products, services, processes) are dependent on where the customer is in the contact cycle. It is recommended that companies develop different customer contact cycles for different businesses and examine how each interaction can be focused and improved.

Customer retention activity begins at the point when the customers sign up to the services. To retain customers the company needs a powerful database, which should store detailed customer profile data and a full communications history, thus allowing the customer base to be segmented and to target specific groups of customers with tailored offerings (eg welcome call, welcome packages, loyalty prices).

A company should develop a set of criteria for selecting the most suitable mechanisms for each customer segment in order to build customer loyalty.

International experience has shown that a 5 per cent improvement in customer retention can increase profits by up to 85 per cent. $^{5}$

The way to understand customer behaviour is to use customer data and clustering methods.

The task of customer clustering requires a heterogeneous population to be separarated into a number of more homogeneous subgroups or clusters. Clustering is an important capability in differentiating processes and services based on customer needs and value.

There are, in fact, two ways to cluster customers. The deductive way uses simple database queries based on a specific hypothesis. For example, assume that the typical ADSL user is a family with children: by querying the database one is able to verify this assumption. The inductive way of clustering is based on discovering unknown patterns in the database by using clustering algorithms. For example, a group of internationally-oriented customers with high economic value and low buying power is discovered. The use of clustering methods facilitates the discovery of unknown patterns. Self-organised maps (SOMs) is a clustering method that allows one to classify a large number of chosen data objects (customers) according to their total similarity, where each datum point 
contains numerous attributes (ie age, turnover, length of contract etc). The SOM builds a multivariation data classification into a multidimensional data spectrum. ${ }^{6}$

\section{Developing customer churn models - Propensity to churn}

Why should a company manage churn rate? International research has shown that it can be at least five times as hard to acquire new customers as it is to keep existing customers. In order to protect market share and profitability, the company should aim to achieve below industry average customer churn rates, which will tend to result in increased profits and higher customer lifetime value.

Methods of reducing churn rates include:

— Tailoring products, services, processes and channels to the customer's wants and needs.

- Tailoring internal processes to the customer's processes.

- Tailoring solutions to the customer's individual profile.

- Implementing loyalty programmes.

- Improving customer services.

- Improving network performance.

- Avoiding creating dissatisfied customers.

Reporting tools should be used to analyse the customer database to identify some of the characteristics of potential customer churn, including:

- Changes in spending or payment patterns; and

- Customers with recurrent or multiple problems or queries.

In cases where indications of an impending churn are identified, proactive steps should be taken to gather further information regarding the customer's level of satisfaction with the service and to identify corrective actions where this satisfaction is not high. $^{7}$

\section{Customer churn analysis}

The cost of churn in the telecommunications industry is large. It costs a great deal more to win new customers than it does to retain current ones. Moreover, frequently, a new customer will churn away before the company can fully recoup its acquisition costs. Customers satisfaction surveys can be misleading as indicators of what drives churn. Mercer found that 80 per cent of churners had previously stated that they were satisfied with their service, but nevertheless churned within 12 months. ${ }^{8}$

One solution is to use data mining techniques in churn analysis to perform two key tasks: prediction (predicting whether a particular customer will churn); and understanding (understanding why particular customers churn).

Data mining is defined as advanced methods for exploring and modelling relationships in large amounts of data. ${ }^{9}$ Types of data are interval (a variable for which the mean makes sense — such as average income or average temperature) and categorical. Categorical data are divided into unary (same value), binary (only two possible levels), nominal (more than two possible levels) and ordinal (more than two possible levels with ordering, eg small, regular, large data.

The data mining process consists of three steps:

1 Data pre-processing (data cleansing, sampling, transformation, variable selection).

2 Analysis (associations analysis, 
multivariate analysis, cluster analysis, prediction).

3 Interpretation (patterns, trends, structures).

The gained knowledge is used for a better understanding of the market (retention, needs, product management, communication and sales).

A churn modelling campaign needs to make a number of decisions: definition of churn; the type of model to build; how to segment the data for modelling; algorithm-specific choices; the size and density of the model set; how to handle the time element; which data to include in the model; and how to calculate derived variables.

Churn is the measurement of the proportion of the customers that leave a service or service provider over a given period. The types of churn can be divided into different segments: voluntary churn (containing controllable reasons and uncontrollable reasons); and involuntary churn. Examples of controllable reasons are going over to the competition ('in system' churn) and cancelling altogether ('out system' churn). Examples of uncontrollable reasons are death, moving out of service area and stolen telephone. Examples of involuntary churn are non-payment, bankruptcy and fraud. The drivers for the controllable reasons are pricing, promotion, network coverage, service dissatisfaction, billing, old/broken equipment, affordability and lack of need.

Having carried out a lot of retention campaigns, the author has found that the major reasons for churn are competition (price difference, marketing), convenience (stoppages, barriers, age), image (homeland associated, age, social status), quality (complaints, numbers of customer care contacts) and price (price elasticity, saving potential, buying power, nationality, age). The key question is how to identify the variables in the data warehouse, that can approximate the churn reasons.

\section{Churn modelling using decision trees}

Churn modelling is an ongoing business challenge. Decision trees are a good choice for modelling because they provide rules that business users understand. Different types of trees include Chi-square automatic interation detection (CHAID) for categorical variables, binned-entropy for continuous values and Gini. Important decision tree parameters are the minimum size of the leaf node, the minimum size of a node to split and the maximum depth of a tree. The challenge of pruning decision trees is to find the best sub-tree.

\section{The time element}

To build an effective model, the data in the model set has to mimic the time frame when the model will be applied. A classical mistake is the latency effect: modelling the present instead of the future. For example, several months of past data (eg February through July) might be used to predict the outcomes in August. Then, one might want to apply the model to predict outcomes in September at the end of August. When is August's data available?

A good model set includes data from several months, a latent month and counts the months back from the latent month. Including a latent month takes model deployment and scoring into account.

\section{Customer data and information}

Building valuable customer relationships requires customer information. This 


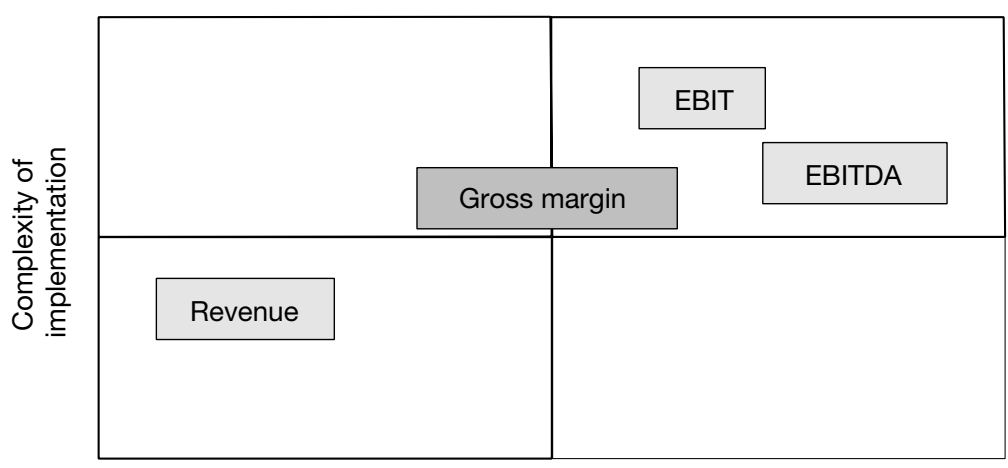

Business benefit

EBIT: earnings before interest and tax; EBITDA: earnings before interest, tax, depreciation and amortisation

Figure 2: Ways of calculating customer profitability

information must be comprehensive and it must reflect the rapidly changing marketplace. Traditional customer surveys are no longer enough. Companies must use multiple sources to collect and update customer information. These should include:

- Customer transaction systems to enable companies to capture highly detailed data on customers' actual purchases, usage patterns, channels of acquisition and relationship histories.

- Customer contact channels that include call centres, retail operations, the internet, welcome programmes etc.

- Market research that provides insights into non-customers.

\section{Defining and measuring data quality}

The crucial factor when building churn models is high quality data. There are four features that influence the data quality: accuracy, completeness, consistency and timeliness. ${ }^{10} \mathrm{~A}$ data quality assurance process consists of a cycle that contains the following four phases: define, measure, analyse (data quality reports) and improve (quality control meeting).

\section{Identifying customer profitability}

When developing retention strategies, the aim is to create a model to predict who will most likely leave in the next month, based on last month's data. The target group is the future churners. The model should predict the future churners better than without a model. When a campaign is defined, the customer's propensity to churn is not the only feature that is incorporated. To maximise the NPV of a campaign, only customers with an NPV $>0$ should be contacted.

Customer profitability is a key parameter in the process of defining a customer strategy. ${ }^{11}$ There are four main factors that influence customer profitability:

- Revenues;

- Product-oriented costs;

- Marketing-oriented costs; and

- Service-oriented costs.

Customer value can be calculated in a number of ways and can vary in benefit as well as ease of implementation. Figure 2 gives an overview of the ways that can be used to calculate customer value. Figure 2 shows that the more sophisticated the approach, the better is the insight throughout the organisation and the 
Table 1: The relevant parameters for calculating NPU of a campaign

\begin{tabular}{|c|c|c|c|}
\hline Parameter & Meaning & Typical values & Source \\
\hline Propensity to churn & $\begin{array}{l}\text { The probability that a } \\
\text { customer cancels during } \\
\text { the next month }\end{array}$ & $\begin{array}{l}1 \% \text { to } 5 \% \text { for each } \\
\text { segment per month } \\
\text { (mean about } 2 \% \text { ) }\end{array}$ & $\begin{array}{l}\text { Analytical CRM based on } \\
\text { the characteristics of the } \\
\text { churners }\end{array}$ \\
\hline Propensity to accept & $\begin{array}{l}\text { The probability that } \\
\text { customer accepts an } \\
\text { offer (eg win back) }\end{array}$ & $\begin{array}{l}\text { Depends on offer and } \\
\text { target group }\end{array}$ & $\begin{array}{l}\text { Analytical CRM based on } \\
\text { the characteristics of the } \\
\text { existing customers }\end{array}$ \\
\hline Duration & $\begin{array}{l}\text { The duration of the } \\
\text { campaign's effect ('How } \\
\text { long/how much longer } \\
\text { the customer stays') }\end{array}$ & $\begin{array}{l}\text { Depends on target group } \\
\text { and, as the case may be, } \\
\text { on the offer (assumption: } \\
6-12 \text { months) }\end{array}$ & $\begin{array}{l}\text { Data mining and } \\
\text { segment manager's } \\
\text { estimations }\end{array}$ \\
\hline $\begin{array}{l}\text { Campaign-specific } \\
\text { costs }\end{array}$ & $\begin{array}{l}\text { Additional costs arising } \\
\text { from campaign } \\
\text { (non-recurring or recurring } \\
\text { costs) }\end{array}$ & $\begin{array}{l}\text { Depends on the product } \\
\text { (partly from the } \\
\text { traffic-mix) }\end{array}$ & $\begin{array}{l}\text { Data mining; } \\
\text { purchase and product } \\
\text { management }\end{array}$ \\
\hline $\begin{array}{l}\text { Variable contribution } \\
\text { margin }\end{array}$ & $\begin{array}{l}\text { The change in turnover } \\
\text { minus the directly } \\
\text { proportional costs of the } \\
\text { service amount }\end{array}$ & $\begin{array}{l}\text { Depends on the product } \\
\text { and, as the case may be, } \\
\text { the } \\
\text { customer/group-specific } \\
\text { product mix }\end{array}$ & Data mining \\
\hline
\end{tabular}

extracted value. The proposed way of calculating customer profitability, earnings before interest, taxes, depreciation and amortisation (EBITDA) represents the lowest level of variable costs by customer.

$$
\begin{aligned}
\mathrm{CM}_{\mathrm{EBITDA}}= & (\text { Revenue })-\text { (cost of sales }) \\
& -(\text { service costs }) \\
& -(\text { network costs }) \\
& -(\text { bad debt expenses }) \\
& -(\text { marketing costs })
\end{aligned}
$$

\section{APPLYING CUSTOMER PROFITABILITY AND PROPENSITY TO CHURN TO DESIGN PROFITABLE LOYALTY CAMPAIGNS}

Having generated the desired customer knowledge (customer clusters, propensity to churn and customer profitability) one can now design the right campaigns to retain customers and increase customer value.

\section{Types of campaigns}

Three kinds of campaign can be distinguished conceptually: win-back, retention and cross-up-selling. A win-back campaign concentrates on customers, that no longer produce turnover for the company. The goal is to get the customer back. A retention campaign concentrates on customers that use the company's services, but are likely to churn in the near future. The goal is to strengthen their loyalty. The last kind of campaign, cross-up-selling, tries to find customers that might be interested in a further product or service. The goal is to sell them a further or upgraded product. Often companies use combinations of the above (eg cross-selling with the effect of retention).

\section{Steps to determining the financial benefits of a campaign}

1 Analytical CRM creates a ranking and identifies the target groups.

2 The marketer defines the campaign (target group, competitive environment, retention, win back, cross-up-selling, channel (inbound vs outbound) and so on). The input is the knowledge from the analytical CRM, the result is the defined campaign

3 The marketer estimates the financial 
impact of a campaign, based on the average values of the target group and the calculation of the costs. The inputs used are ratios like the propensity to churn, contribution margin and so on. One has to make assumptions about the divergence loss and to calculate the estimated costs. The result is a first estimation of the NPV.

4 Based on the estimations of step 3, the calculation can be improved iteratively (eg changed incentives or a more detailed target group). The result is an adapted campaign and an improved NPV.

5 Customers are selected depending on the defined levels (eg the level of the propensity to churn or the contribution margin). The campaign designer can now calculate the value of the campaign using the individual values of each customer.

6 The campaign is launched.

7 Evaluation of the campaign's success.

\section{Fixed and variable costs and the contribution margin}

In the financial evaluation of a campaign, only the variable costs (eg discount for customer loyalty) are relevant. These vary depending on whether a campaign is started or not. To evaluate the success, the variable costs and the contribution margin are needed for the products concerned. The fixed costs (eg leasing costs) are not influenced by a campaign, therefore they are irrelevant to the financial evaluation.

If the full costs are used to evaluate the profitability of products or customer segments, the result can lead to a wrong conclusion. For example, a product/segment has a positive contribution margin if only the variable costs are considered. If the fixed costs are included the contribution margin is negative.

\author{
Contibution margin $(\mathrm{CM})=$ \\ retail price per minute after VAT \\ - variable costs per tax minute
}

If the production of the product is stopped, or the segment is no longer considered, the fixed costs are divided among the remaining products/segments and, therefore, increase. As a result, formerly profitable products/segments might also acquire negative contribution margins and be halted. This can lead to a vicious circle in which all products/segments become unprofitable.

\section{The NPV of a campaign}

To be able to compare campaigns for different products, the variable costs and/or the contribution margin should be considered. The financial impact of a campaign is calculated with the NPV per customer based on the variable costs and the expected contribution margin (see Table 1).

\section{General formula for calculating the NPV}

This section provides a general method of calculating the expected NPV of a customer subject to a retention campaign. The calculation extends over a finite time period. Time is a discrete variable. In this simple model, the monthly billing cycle drives a monthly customer decision regarding changing provider. This model is valid for markets where customers are not bound into a minimum contract period. A typical example is the Swiss telecommunications market, where customers can change provider at any time (in this model at the end of the month) at no cost.

Equation (1) expresses the expected customer NPV as a function of the churn rate, $p_{t}$; the discount offer, $d_{t}$; and the customer's constant monthly contribution margin (profit), $w$. The index, $t$, in the 


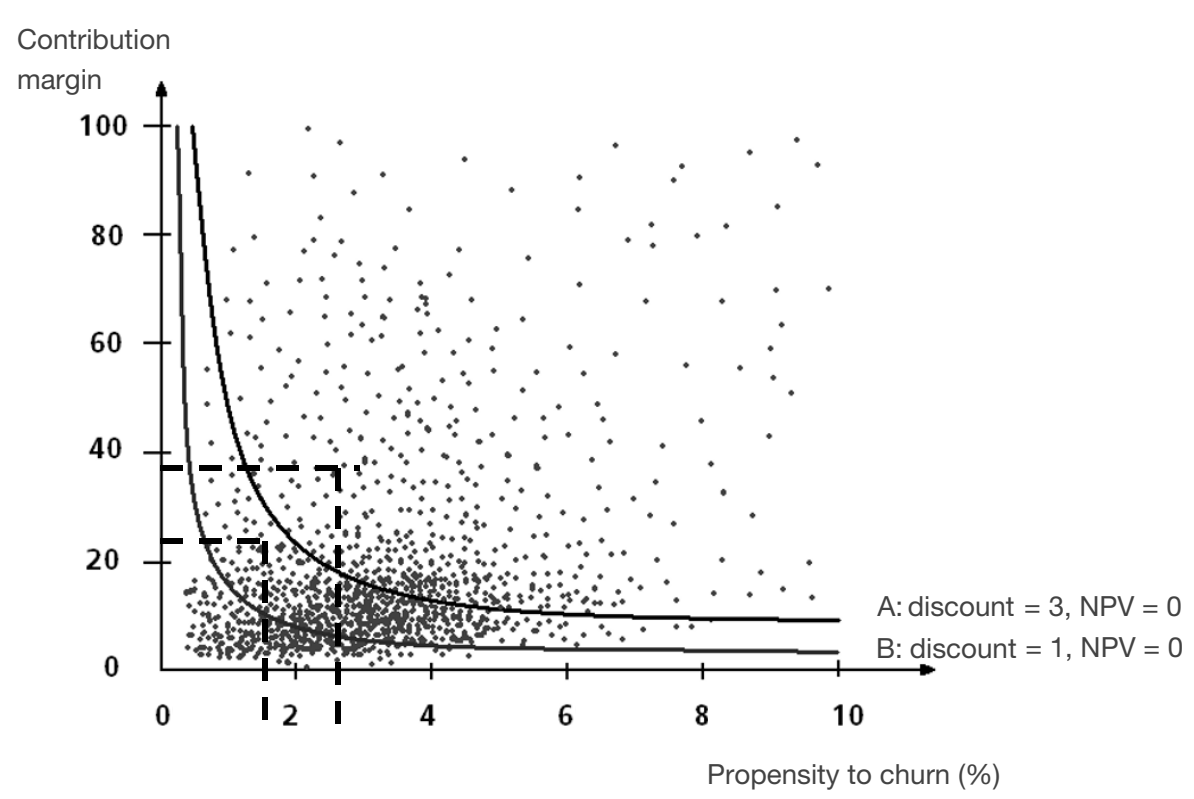

Figure 3: Profitable and non-profitable customers in a retention campaign

churn rate and the rebate amount are time dependent. The contribution margin is assumed to be time independent. Future cash flows are discounted at a monthly discount rate, $r$. A typical value for $r$ is 1 per cent, a value that is much higher than typical risk-free interest rates. This choice of $r$ reflects the uncertainty in the value of $w$ and $p_{t}$. The summation is run over a certain time period, typically in the range of 12 to 36 months.

$$
\langle N P V\rangle=\sum_{t} \frac{w \cdot\left(\Pi_{t}\left(1-p_{t}\right)-d_{t}\right.}{(1+r)^{t}}
$$

\section{Retention case study: 'Students'}

The following case study examines the relationship between contribution margin and churn rate.

Young customers aged less then 25 years should be bound with the weekend discount offer. There are no one-off campaign costs (inbound sales). The customer has to abandon a preselection and must generate traffic turnover valued at at least SwFr 3 per month on weekdays.
If a campaign is launched, only customers with a positive NPV should be accounted for (see Figure 3).

The curves show the line for $\mathrm{NPV}=0$ for situation $\mathrm{A}$, with a discount of SwFr 3 per month and situation B, with a discount of SwFr 1 per month. Customers to the right of curve A have an NPV $>0$, those to the left of the curve have an NPV $<0$.

The earnings of a campaign can be maximised only if profitable customers $(\mathrm{NPV}>0)$ are selected.

\section{The development of the churn rate during a campaign}

To model the development of the churn rate during a campaign, the assumption is made that the churn rate decreases regularly because customers are incentivised to stay. Equation (2) corresponds to this criterion and shows a possible calculation of the varying churn rate, $p_{t}$ depending on the time, $t$.

Parameters $a$ and $b$ are constants which influence the size of the churn rate. They are based on marketing experiences 
Table 2: Monthly churn rate and the probability of staying by months $t$.

\begin{tabular}{lll}
\hline $\boldsymbol{t}$ & $\begin{array}{l}\text { Monthly churn rate } \\
\text { (with a campaign) (\%) }\end{array}$ & $\begin{array}{l}\text { Monthly probability to stay } \\
\text { (with a campaign) (\%) }\end{array}$ \\
\hline 1 & 2.00 & 98.00 \\
2 & 1.50 & 98.50 \\
3 & 1.20 & 98.80 \\
4 & 1.00 & 99.00 \\
5 & 0.86 & 99.14 \\
6 & 0.75 & 99.25 \\
7 & 0.67 & 99.33 \\
8 & 0.60 & 99.40 \\
9 & 0.55 & 99.45 \\
10 & 0.50 & 99.50 \\
11 & 0.46 & 99.54 \\
12 & 0.43 & 99.57 \\
\hline
\end{tabular}

and depend on the market dynamics (competition, penetration rate, products, customer behaviour etc).

$$
p_{t}=\frac{1}{a \cdot(t+b)}
$$

If $t$ increases during the campaign, the churn rate will decrease. This formula is only one of several possibilities for modelling a reasonable development of the churn rate.

In order to define the appropriate parameters, customer behaviour is very important. Customer clustering gives you the information required to define the customer churn behaviour. A high-tech cluster may have a different churn rate behaviour than a price-sensitive cluster. The differentiation of the customer churn behaviour in each cluster provides a more realistic development of the churn rate. Table 2 shows the development of the churn rate if constant $a$ is set to $16 \frac{2}{3}$ and constant $b$ is set to 2. Future calculations are based on these values.

The effect of the reduced churn rate during a campaign on the proportion of retained customers is shown in Figure 4. In this case, the campaign's duration is six months. The explanation how the values are calculated is delivered later.

In Figure 4, line B shows the trend if no campaign is launched; the proportion of retained customers is regularly reduced. If a campaign is launched, the result looks quite different (line A). For the first six months the rate of decrease of customers is slower (ie while the campaign is running). Even after the end of the campaign $(t=7)$, the number of retained customers stays higher than without a campaign. The campaign benefit is the difference between lines $A$ and $\mathrm{B}$ at a specific time period.

\section{The campaign's effect on NPV}

When the benefit of a campaign is calculated for a specific target group, its NPV has to be compared with the NPV of the same target group if they were ignored in the campaign. To calculate the customer's NPV, the contribution margin is multiplied by the probability of staying. If a rebate is offered (eg SwFr 3 for each month during the campaign), this has to be subtracted from the remaining contribution margin. The result is now divided by the discount rate to take into account the time value of money.

Equation (3) shows the calculation of the NPV if no campaign is carried out. The churn rate is time independent as is the probability of staying with the provider. The product symbol in 


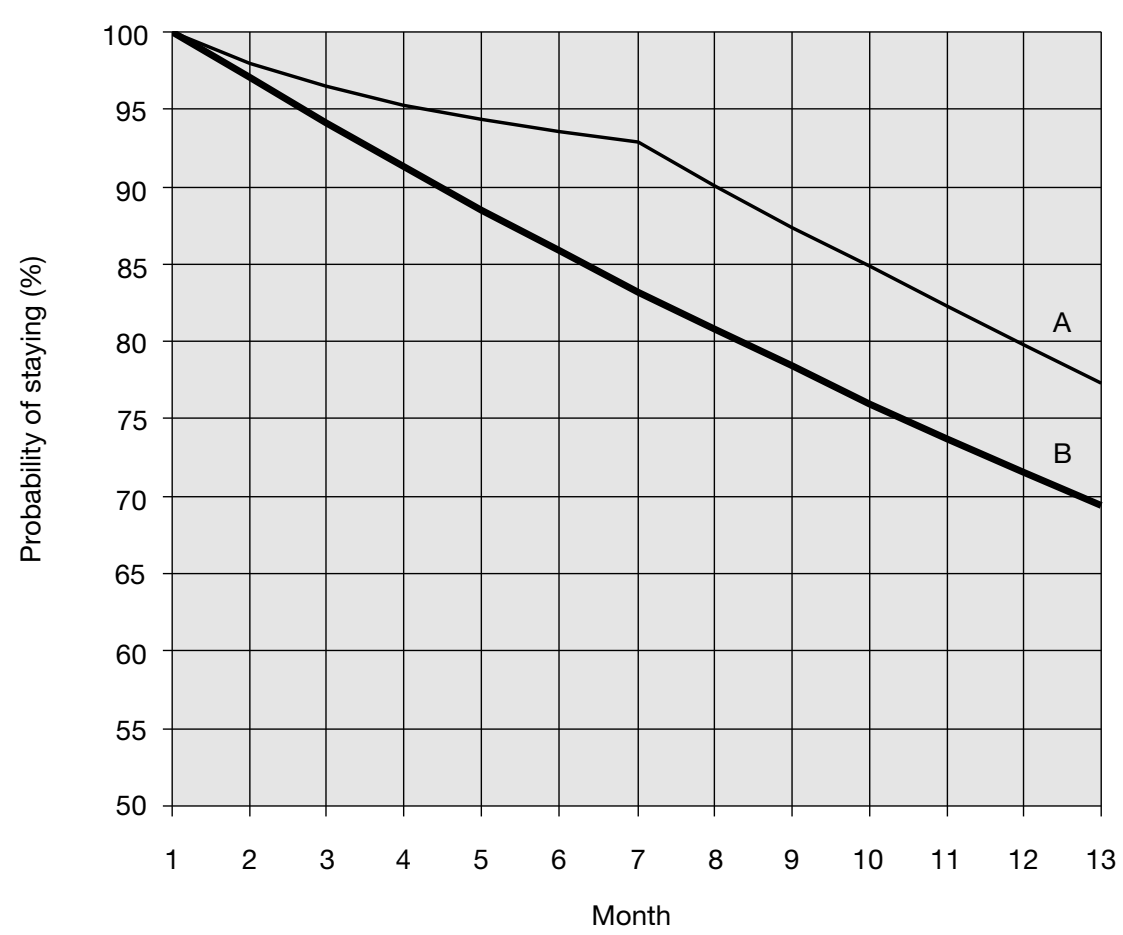

- accumulated proportion of retained customers in target group (no campaign) - accumulated proportion of retained customers in target group (with campaign)

Figure 4: The proportion of retained customers.

Equation (1) can therefore be replaced by the exponent $t$. The considered time frame starts at $t=1$ and ends at $t=\mathrm{T} 2$. The churn rate, $p_{\text {churn }}$ is time independent because no campaign is carried out.

The NPV for this period can be calculated as:

$$
\left\langle N P V_{\text {nocampaign }}\right\rangle=\sum_{t=1}^{T 2} \frac{w \cdot\left(1-p_{\text {churn }}\right)^{t}}{(1+r)^{t}}
$$

Equation (4) shows the calculation of NPV if a campaign is carried out. The churn rate decreases during the campaign, and therefore the proportion of retained customers will increase. The customer's probability of staying till month $t$ is the product of the probabilities of staying during the previous months. The product symbol (instead of using the exponent $t$, if the propensity to churn is time independent) is used for the calculation of the probability of staying, because of the actual variable churn rate (as opposed to the variant if no campaign is carried out). T1 is the last month of the campaign's duration. T2 is the last considered month after the campaign. (see equation (4) below).

The additional profit of a campaign, $\triangle \mathrm{NPV}$, is the difference between the NPV when a campaign is carried out and the NPV if no campaign is

$$
\left\langle N P V_{\text {campaign }}\right\rangle=\sum_{t=1}^{T 1} \frac{w \cdot \prod_{n=1}^{t}\left(1-\frac{1}{a \cdot(n+b)}\right)-d}{(1+r)^{t}}+\sum_{t=T 1+1}^{T 2} \frac{w \cdot \prod_{n=1}^{T 1}\left(1-\frac{1}{a \cdot(n+b)}\right) \cdot\left(1-p_{\text {churn }}\right)^{(t-T 1)}}{(1+r)^{t}}
$$


Table 3: Variant if no campaign is carried out.

\begin{tabular}{rllll}
\hline \multicolumn{1}{c}{$\boldsymbol{t}$} & $\begin{array}{l}\text { Monthly churn } \\
\text { rate (\%) }\end{array}$ & $\begin{array}{l}\text { Accumulated proportion of } \\
\text { retained customers in target } \\
\text { group (no campaign) }\end{array}$ (\%) & $\begin{array}{l}\text { Monthly NPV } \\
\text { (SwFr) }\end{array}$ & $\begin{array}{l}\text { Accumulated NPV } \\
\text { (SwFr) }\end{array}$ \\
\hline 1 & 3.0 & 97.00 & 48.02 & 48.02 \\
2 & 3.0 & 94.09 & 46.12 & 94.14 \\
3 & 3.0 & 91.27 & 44.29 & 138.43 \\
4 & 3.0 & 88.53 & 42.54 & 180.97 \\
5 & 3.0 & 85.87 & 40.85 & 221.82 \\
6 & 3.0 & 83.30 & 39.23 & 261.05 \\
7 & 3.0 & 80.80 & 37.68 & 298.74 \\
8 & 3.0 & 78.37 & 36.19 & 334.92 \\
9 & 3.0 & 76.02 & 34.76 & 369.69 \\
10 & 3.0 & 73.74 & 33.38 & 403.06 \\
11 & 3.0 & 71.53 & 32.06 & 435.12 \\
12 & 3.0 & 69.38 & 30.79 & 465.90 \\
\hline
\end{tabular}

carried out:

$$
\begin{aligned}
\langle\Delta N P V\rangle= & \left\langle N P V_{\text {campaign }}\right\rangle \\
& -\left\langle N P V_{\text {nocampaign }}\right\rangle
\end{aligned}
$$

\section{Calculating the NPV of a campaign}

The formulae above are now applied to an example. Imagine a target group of 10,000 similar customers belonging to the same customer cluster (ie the same contribution margin and churn rate). Each of these customers is representative of the whole target group. A contribution margin of SwFr 50 and a discount rate of 1 per cent per month are assumed.

First, the non-campaign variant is presented. The churn rate of 3 per cent per month is time independent. The proportion of retained customers is reduced regularly (see Table 3 ).

Now, the campaign variant is presented. The campaign's duration is six months. In this time the customer gets a rebate of SwFr 3 per month, which leads to a reduction in the churn rate. Even months after the campaign's expiration, the proportion of retained customers is higher than in the non-campaign variant because the number of retained customers was increased as a result of the campaign.

The last column of Table $4(\Delta \mathrm{NPV})$ shows the difference between the campaign and the non-campaign variants with regard to NPV. During the first six months, $\triangle \mathrm{NPV}$ is negative due to the rebate that was offered. Afterwards, $\triangle \mathrm{NPV}$ is positive because of the higher proportion of retained customers. An accumulated NPV of SwFr 486.87 results after 12 months, which is SwFr 20.96 higher than if no campaign had been carried out.

As previously mentioned, the customers in the target groups have similar characteristics. An individual customer's values are representative of the whole target group. To calculate the NPV of the whole campaign, therefore, the NPV of a customer can be extrapolated. $\mathrm{N}$ denotes the number of customers in the target group (assume 10,000).

$$
\begin{aligned}
\left\langle\Delta N P V_{\text {target group }}\right\rangle= & N \cdot\left(\left\langle N P V_{\text {campaign }}\right\rangle\right. \\
& \left.-\left\langle N P V_{\text {nocampaign }}\right\rangle\right)
\end{aligned}
$$

Using the data in Tables 3 and 4, the additional NPV due to the campaign can be calculated for the target group:

$$
\begin{aligned}
< & \Delta N P V_{\text {target group }}>=10,000 \star(486.87 \\
& -465.90)=10,000 \star 20.96 \\
& =\text { SwFr 209,600. }
\end{aligned}
$$

In this case their campaign is profitable. 
Table 4: Variant if a six-month campaign is carried out.

\begin{tabular}{|c|c|c|c|c|c|c|}
\hline$t$ & $\begin{array}{l}\text { Rebate } \\
\text { (SwFr) }\end{array}$ & $\begin{array}{l}\text { Monthly churn } \\
\text { rate }(\%)\end{array}$ & $\begin{array}{l}\text { Accumulated proportion of } \\
\text { retained customers in } \\
\text { target group (with } \\
\text { campaign) (\%) }\end{array}$ & $\begin{array}{l}\text { Monthly NPV } \\
\text { (SwFr) }\end{array}$ & $\begin{array}{l}\text { Accumulated } \\
\text { NPV (SwFr) }\end{array}$ & $\Delta \mathrm{NPV}$ \\
\hline 1 & 3 & 2.00 & 98.00 & 45.54 & 45.54 & -2.48 \\
\hline 2 & 3 & 1.50 & 96.53 & 44.37 & 89.92 & -4.22 \\
\hline 3 & 3 & 1.20 & 95.37 & 43.37 & 133.29 & -5.14 \\
\hline 4 & 3 & 1.00 & 94.42 & 42.48 & 175.77 & -5.19 \\
\hline 5 & 3 & 0.86 & 93.61 & 41.68 & 217.45 & -4.37 \\
\hline 6 & 3 & 0.75 & 92.91 & 40.93 & 258.39 & -2.67 \\
\hline 7 & 0 & 3.00 & 90.12 & 42.03 & 300.41 & 1.68 \\
\hline 8 & 0 & 3.00 & 87.42 & 40.36 & 340.78 & 5.85 \\
\hline 9 & 0 & 3.00 & 84.79 & 38.76 & 379.54 & 9.86 \\
\hline 10 & 0 & 3.00 & 82.25 & 37.23 & 416.77 & 13.71 \\
\hline 11 & 0 & 3.00 & 79.78 & 35.76 & 452.53 & 17.41 \\
\hline 12 & 0 & 3.00 & 77.39 & 34.34 & 486.87 & 20.96 \\
\hline
\end{tabular}

\section{Evaluation of the campaign's success}

When a campaign is carried out, the company invests money with the aim of reducing the churn rate. Thus the company is interested in knowing the quality of a churn prediction model and the effect of a campaign on the churn rate.

To be able to measure the success of models or campaigns, control groups are needed. When a campaign is planned, a random selection of all potential campaign customers is taken to build a control group called 'control group I' (see Figure 5). A churn predictive model is then developed and applied to all potential campaign customers to identify those who have a high churn rate. They are the target group. A part of this target group is used to build another control group, 'control group II'. After a specific time the churn rate of both control groups are compared to evaluate the predictive model. If control group I has a lower churn (eg 5 per cent) than control group II (eg 10 per cent), then the quality of the model was high because it is capable of identifing more churners than a random selection.

During the planning of a campaign, the churn rates have to be estimated on the basis of marketing experience (eg competition analysis) or derived from the calculation of a predictive model or a combination of both methods (Figure 6, lines A1 and A2). The quality of the churn models can be measured during or after the campaign (Figure 6, lines B1 and B2). This can be done in an analogue fashion to the evaluation of the predictive model. The churn of control group II (Figure 5, eg 10 per cent) is compared with the churn of the campaign participants (Figure 5, eg 7 per cent). The area between lines B1 and B2 in Figure 6 shows the actual numbers of additional customers that stayed. The quality of the method for calculating the success of the campaign was good if this area is equal to or greater than the estimated value (area between lines A1 and A2).

The campaign benefit is the additional contribution margin due to the additional customers minus the campaign costs.

The knowledge gained from the presence of the control group can be used to make better estimations for the next campaign, because the behaviour of the customers could be measured.

\section{CONCLUSION}

This paper showed a method of calculating the NPV and profitability of 


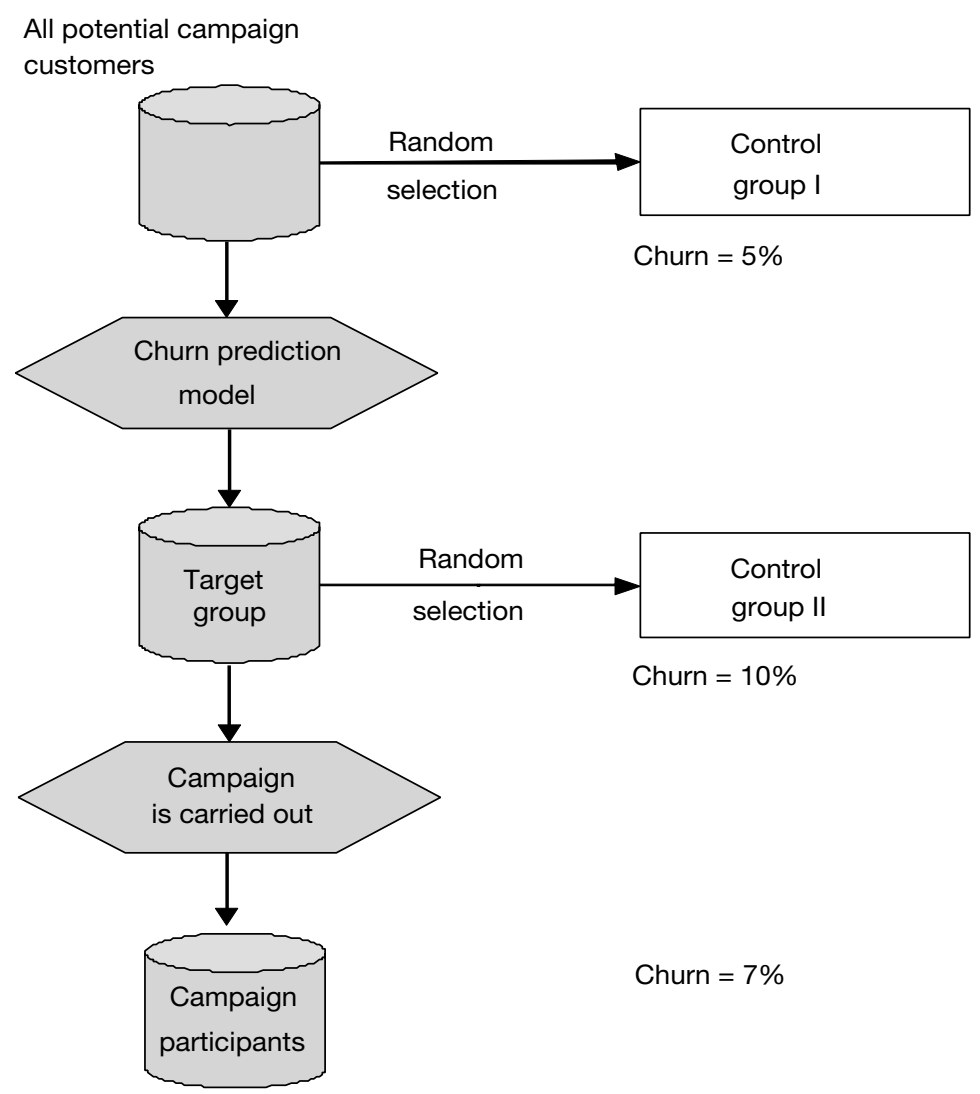

Figure 5: Measuring the campaign and modelling effect

a campaign in order to design profitable customer strategies. Depending on the different parameters (clusters, contribution margin, discount, discount rate, churn rate), the result of the calculation varies and the user of the model should be aware of this. To get a reasonable result in practice, a good estimate of the different parameters is necessary.

The expected profitability of a campaign should not be the only criterion that decides whether the campaign is carried out or not. Even an unprofitable campaign might have a positive effect on the company's other products or services in the future.

To summarise, the following aspects have to be considered by developing profitable retention strategies:

— Defining churn, especially differentiating between interesting and uninteresting churn.

- Identifying data requirements for the churn model.

- Focusing on reducing the root causes of churn.

- Churn modelling is never a one-time event and needs to be incorporated into the business process.

- Developing the right capabilities.

- Using existing customer information to produce knowledge: value, needs and propensities.

- Delivering the generated customer knowledge to the customer touchpoints in order to add value both to the customer and to the organisation.

- Establishing a churn and campaign management process across the organisation.

— Introducing the right tools. 


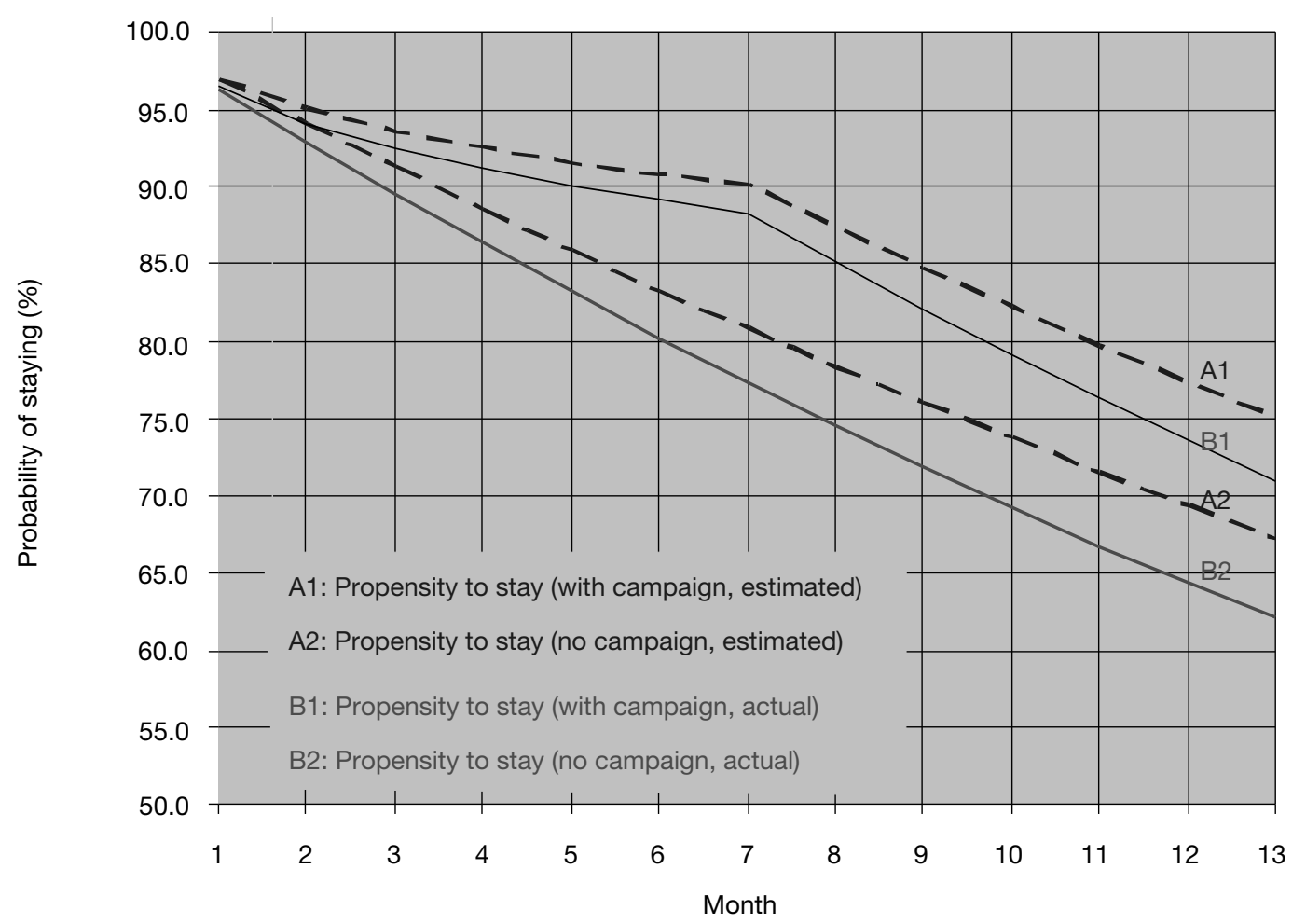

Figure 6: Comparison of estimated and actual probabilities of staying

- When a campaign is developed, the purpose (retention, win back, cross-/up-selling) and the competitive environment have to be identified.

- In the calculation of the financial impact of a campaign, only those turnovers and costs/contribution margins which are directly influenced by the decision to launch a campaign or not should be considered.

- The important assumptions (propensity to churn, divergence loss, duration of the effect of a campaign) should be questioned critically (building scenarios) and analysed to measure the success.

\section{References}

1 Ryals, L. (2002) 'Measuring risk and returns in the customer portfolio', Journal of Database Marketing \& Customer Strategy Management, Vol. 9, No. 3, pp. 219-227.
2 Grand, P. (2002) 'Achieving excellent customer relationships', Manual of Customer Interface Management, BWCS Ltd, pp. 69.

3 Hawley, D. and Entner, R. (2003) 'The intelligent wireless operator', Wireless/Mobile Services report, Yankee Group.

4 Xevelonakis, E. (2004a) 'Building churn prediction models', presented at the IIR Annual Conference on Optimising CRM \& Retention Strategies, Nice, France.

5 Grand, P. (2002) op.cit.

6 Xevelonakis, E. (2004b) 'Forcasting churn and exploiting data for customer retention strategies', IIR's Thirteenth Annual Conference on Telecoms Market Forecasting, Prague.

7 Coyles, S. and Gokey, C. (2002) 'Customer retention is not enough', The McKinsey Quarterly, No. 2, www.mckinseyquarterly.com.

8 Kolko, J. (2003) 'How to stop broadband churn before it starts', Forrester, www.forrester.com.

9 Fayyad, M. U., Piatetsky-Shapiro, G., Smyth, P. and Uthurusamy, R. (1996) 'Advances in Knowledge Discovery and Data Mining', MIT Press, Menlo Park, CA.

10 English, L. P. (1999) 'Improving data warehouse and business information quality', Wiley, USA.

11 Storbacka, K. (1995) 'The nature of customer relationship profitability - Band 55', Helsingfors, Helsinki, Finland. 